\title{
Trilhas de Telenovelas Globais e o Mercado Musical nos anos 1980 e 1990
}

\author{
Global Soap Opera's soundtracks and the music \\ market in the 80's and 90's
}

\begin{abstract}
Heitor da Luz Silva I htr428@gmail.com
Graduado em Comunicação Social, com habilitação em Cinema e Vídeo, pelo Instituto de Artes e Comunicação Social da Universidade Federal Fluminense no ano de 2005. Mestre pelo Programa de Pós Graduação em Comunicação, Imagem e Informação da UFF em 2008, onde desenvolveu pesquisa ligada à linha de Comunicação e Mediação intitulada Rio de Janeiro, Rock e Rádio FM: a incursão da Fluminense FM "A Maldita" e da Cidade "A Rádio Rock" no domínio das guitarras. Doutorando no mesmo PPGCOM desde março de 2009, onde desenvolve o projeto "Indústria da Música, Televisão e Reality Show Musical". Professor do Curso de Comunicação Social (Jornalismo e Publicidade) do Centro Universitário de Volta Redonda (UNIFOA). Membro, desde 2006, do Labcult (Laboratório de Cultura e Tecnologias da Comunicação), coordenado pela Professora Doutora Simone Andrade Pereira de Sá, e da IASPM (International Association for the Study of Popular Music), desde 2007.
\end{abstract}

Resumo: Procurando contribuir para a análise das relaçôes entre televisão e indústria da música no Brasil, o objetivo do artigo é investigar o papel das trilhas das telenovelas globais na história da indústria musical entre os anos 1980 e 1990. Busca-se verificar se essas mídias cumpriram um papel semelhante ao dos anos 1970, privilegiando artistas e gêneros mais bem posicionados dentro da hierarquia cultural brasileira, mantendo um diálogo ativo com os preceitos do "padrão Globo de qualidade" estabelecido à época.

Palavras-chave: Trilha sonora de telenovela; Indústria da Música; Rede Globo de Televisão

Abstract: Aiming to contribute to the analysis of the relationship between television and music industry in Brazil, the objective of the article is to investigate the role of the discs of TV Globo's soap operas in the history of the musical industry between years 1980 and 1990. It seeks to verify if that media had continued fulfilling a similar role to the one of years 1970, focusing on artists and genres best located within the Brazilian cultural hierarchy, keeping active the precepts of the "standard Globo of quality" established at that time.

Keywords: Soap Opera's soundtrack; Music Industry; TV Globo Network. 


\section{Introdução}

Apesar da relevância do tema, é intrigante perceber que as discussôes sobre o papel da televisão brasileira na indústria musical permanecem ainda pouco exploradas pela academia, à exceção mais notável dos festivais dos anos 1960 (MORELLI, 1991;

NAPOLITANO, 2010). Salta aos olhos a ausência de pesquisas, por exemplo, centradas no papel dos programas de auditório e das trilhas sonoras de telenovelas nesse sentido.

Em relação às telenovelas, encontrou-se, na produção da última década, apenas um artigo na área da comunicaçáo sobre o tema (TOLEDO, 2007) e ainda reflexóes mais pontuais articuladas ao papel da gravadora global 'Som Livre' (DIAS, 2005).

Este artigo visa a preencher parte dessa lacuna ao investigar o papel das trilhas das telenovelas globais na história da indústria musical entre os anos 1980 e 1990.

A finalidade é de, do ponto de vista dos estudos de comunicação, contribuir para as pesquisas no âmbito da história das mídias sonoras. No campo da História, sobretudo, existem algumas análises e levantamentos relevantes em relação à função dos discos de trilhas de telenovelas como mídias fundamentais na consolidação da música brasileira no mercado fonográfico ao longo da década de 1970, marcada pela distinção social e midiática entre uma parcela da produção mais e outra menos prestigiada culturalmente em torno do poder de instituição do rótulo MPB (ARAÚJO, 2003; NAPOLITANO, 2010; SCOVILLE, 2008). No entanto, pelo fato de se limitarem ao período da ditadura militar, essas pesquisas merecem desdobramentos.

Para a produção deste artigo, realizou-se um levantamento empírico a fim de discutir o papel dessas trilhas globais para o mercado fonográfico a partir da década de 1980, levando-se em conta a proliferação de expressóes musicais que surgiram desse período em diante e que deram novos arranjos para o processo de hierarquizaçáo cultural que envolve o circuito de sua produção, circulação e consumo. Quais foram os segmentos mais e menos privilegiados pela seleção das trilhas de telenovelas globais? Houve uma predileção por artistas e gêneros mais bem posicionados dentro da hierarquia cultural? Em que medida? Para a coleta de dados, o acesso ao site www.teledramaturgia.com.br, domínio mantido pelo pesquisador Nilson Xavier que disponibiliza o acervo de todos os discos de trilhas de telenovela da história da TV brasileira, serviu como referência fundamental.

O recorte cronológico estabelecido pela pesquisa leva em consideração o período em que a concentraçáo de poder nas grandes gravadoras permitiu uma percepçáo mais clara do que na atualidade da formaçáo de "ondas" segmentadas em torno de determinadas rotulaçóes relacionadas aos gêneros musicais que demarcaram de certa forma a história da indústria, seja em momentos de retração ou de expansão do mercado fonográfico. Assim, procurou-se evitar o momento atual mais pulverizado e disperso nesse sentido, em virtude das 
tecnologias digitais e da internet que contribuíram para uma diversificação maior do mercado, e que merece um estudo à parte, para que a análise se centrasse apenas nas décadas de 1980 e 1990.

Vale registrar ainda nessa introdução os parâmetros que balizam as categorias de gênero musical que aqui foram utilizadas para a análise dos dados. Essas procuraram corresponder a nomenclaturas que se tornaram predominantemente correntes para definir no circuito os artistas que surgiram renovando esteticamente o cenário musical ao consolidarem novos fenômenos do comércio fonográfico a partir da década de 1980. Buscou-se privilegiar expressóes musicais que definiram novos grandes marcos pelos quais a indústria ficou historicamente reconhecida por seus investimentos em relação aos anos 1980 e 1990 (vinculadas ao pop-rock, à música sertaneja, ao axé music, ao funk carioca e ao pagode romântico), considerando-se ainda duas categorias relevantes para o período da década de 1970 (MPB e música cafona/ brega) que tanto se renovaram quanto mantiveram no mercado artistas lançados anteriormente ao longo desse período.

Trata-se de um recorte metodológico, o que não significa desprezar a existência de tensóes, transformaçóes e rearranjos históricos reais nessas classificaçôes, como a incorporação de diversos nomes que surgiram ligados ao pop-rock ao rótulo de MPB comprova. Reconhecendo, no entanto, as limitaçóes dessa opçáo, aposta-se no valor de sua produtividade em relação aos objetivos propostos. Sobre as categorias de gênero adotadas, cabe deixar claro ainda que: a) A música sertaneja a que se refere aqui diz respeito às suas representaçóes mais modernas estabelecidas por duplas como Chirtãozinho \& Xororó, Zezé di Camargo \& Luciano e cantoras como Roberta Miranda, no período estudado, deixando de lado os representantes do repertório chamado caipira tradicional, mais dotado de legitimidade cultural no circuito (ALONSO, 2011); b) O pagode romântico diz respeito aos artistas que, após o sucesso do grupo Raça Negra, se estabeleceram no mercado fonográfico dos anos 1990 a partir de uma nova estética que se contrapunha aos valores tradicionais do samba; c) $\mathrm{Na}$ categoria axé music, foram considerados tanto os representantes das matrizes culturais carnavalescas dos blocos afro e dos blocos de trios (como a Banda Eva e o Chiclete com Banana) quanto os grupos de pagode da Bahia (como o É o Tchan); d) Na música brega, estão catalogados os representantes e os herdeiros da tradição cafona dos anos 1970, segundo a classificação de Araújo (2003), artistas de grande sucesso comercial e pouco prestígio que não foram classificados como Rock, nem como MPB e que náo se encaixam nas três categorias anteriores, como José Augusto e Rosana.

\section{Rede Globo de televisão, trilhas sonoras de telenovelas e o mer- cado da música a partir da década de 1970}

A partir do final dos anos 1960, cada vez mais as gravadoras se tornaramagentes centrais nos rumos tomados pelo mercado musical, algo que se consolida na década seguinte com o refinamento de sua racionalização. Essas mudanças não significaram a perda da importância da atuação da 
televisão para a indústria da música, mesmo depois do fim dos festivais que, do ponto de vista do mercado fonográfico, serviam de teste para a revelação de novos artistas e canções. ${ }^{1} \mathrm{O}$ poderio da emergente Rede Globo de Televisão, concentrando a audiência cada vez de modo mais expressivo a partir dos anos 1970 ao consolidar um processo de integraçáo nacional promovido com a anuência dos governos da ditadura militar até o período de abertura política (KEHL, 1986), é fundamental para se compreender o conteúdo das transformaçóes no papel da TV na cadeia produtiva e nos valores culturais presentes no circuito da música.

O produto musical era tão importante para emissora líder absoluta em audiência que, mesmo diante das dificuldades enfrentadas pelas apostas no formato dos seus festivais e de programas como o 'Som Livre Exportação', a Globo insistia em se inserir na indústria da música, o que, no meio desse processo, culminou no lançamento do braço fonográfico da corporação, a gravadora 'Som Livre', apoiada a princípio no forte respaldo comercial que os primeiros discos das trilhas sonoras de suas telenovelas obtiveram na parceria de um ano com a Philips. Tais trilhas podem ser percebidas como o eixo articulador a partir do qual, desde o início dessa década, a Rede Globo se apresentava como um agente fundamental no mercado fonográfico, contribuindo decisivamente para a sua renovação, através da divulgação de novas cançôes e de novos artistas, bem como na solidificação de muitos dos lançados na década anterior, para um público cada vez mais expressivo (DIAS, 2005; MORELLI, 1991; SCOVILLE, 2008; TOLEDO, 2007).

Em meio a um intenso jogo de interesses que envolviam acordos tácitos e tensóes com as imposiçôes políticas e morais da ditadura militar à época, as estratégias empresariais da emissora passavam a ter como uma de suas principais finalidades angariar prestígio social. Nesse sentido, é notável o papel que a concepção do "Padrão Globo de qualidade" obteve para que a noção de modernização operada pela Rede Globo estivesse intimamente relacionada a um ideal de "higienização" e de "assepsia" de sua programação na década de 1970. A concepção se relaciona com uma série de convençóes que formataram o seu novo padrão de programação, privilegiando cada vez mais "os programas pré-gravados, passíveis de um controle interno mais rigoroso" que passava por uma diminuição "da improvisação, da informalidade e do inesperado" (RIBEIRO \& SACRAMENTO, 2010, p.119). Com vistas a se atingir esse ideal, além do lançamento do 'Fantástico' e do 'Globo Repórter' (dirigido por cineastas consagrados e adotando uma linguagem inovadora), ambos saudados pela crítica como "bons exemplos" de modernização da televisão, a telenovela passa a ser um elemento chave, transformando-se significativamente. $O$ gênero se rearticulava esteticamente para atingir o gosto da crítica cultural, afastando-se das suas matrizes latino-americanas e dialogando cada vez mais com paradigmas de produção artística consagradas, como os clássicos da literatura brasileira e tramas elaboradas por autores renomados do teatro.

Nesse contexto, a música representava não somente um reflexo dessas transformaçóes, mas tornava-se um elemento fundamental a partir do qual 
se redefinia o conteúdo da programação, seja em espaços como os musicais do Fantástico, precursores do videoclipe, seja naquele que já era e continuava sendo o eixo principal de sua linha de programação, as telenovelas.

É dentro dessa realidade que salta aos olhos de Araújo (2002, p.301-302) a quantidade expressiva de nomes como Tom Jobim, Nara Leão, Gilberto Gil e Milton Nascimento em trilhas sonoras nacionais de novela da emissora a partir do $1^{\circ}$ produto lançado pela indústria fonográfica relacionado ao gênero televisivo em contraste com a ausência de nomes de sucesso comercial ainda mais expressivo, mas associados ao rótulo "cafona", como Waldick Soriano, Odair José, Paulo Sérgio e Nelson Ned. Isso nas mais de 600 faixas de cançôes gravadas em 48 LPs e 10 compactos lançados entre 1969 e 1978. Aliada à expurgação de rostos como os de Odair José e Waldick Soriano de programas como 'Som Livre Exportação' (paulatina, pois ambos participaram dos primeiros), do 'Globo de Ouro' e dos musicais do 'Fantástico', ganham-se mais dados para concordar com o que propóe o autor ao revisar a bibliografia sobre a imagem de representação modernizante adotada a partir da implantação do "Padrão Globo de qualidade" em sua programação.

Para o autor, a “(...) 'imagem asséptica' vinha acompanhada de uma 'sonoridade asséptica' [que] (...) era incompatível com as cançôes do repertório 'cafona”, sendo o que denomina como estética da MPB mais apropriada "ao projeto de se vender a ideia de um país economicamente forte, moderno e desenvolvido" (2002, p.303). ${ }^{2}$

A partir do período de redemocratização, com a indústria fonográfica e o mercado televisivo sofrendo modificações, pressupóe-se que novas relaçóes tenham se estabelecido com a Rede Globo. A incorporaçáo dos diversos artistas de distintos segmentos, como no programa de Chacrinha (que, de volta à emissora em 1982, incluía tanto os artistas do BRock quanto os representantes da música brega, bem como os da própria MPB), é um indicativo dessas transformações. Com modificações na relação entre televisão e indústria musical que diversificaram o mercado e renovaram o star system nas décadas seguintes, propomo-nos a investigar possíveis transformaçóes no papel particular das trilhas das telenovelas globais nessa história entre os anos 1980 e 1990 nas seçóes seguintes. De que forma elas participaram mediando o surgimento e a consolidação dos artistas e dos diversos segmentos que se estabeleceram no mercado de música a partir de então? A MPB manteve sua hegemonia na seleção das faixas das trilhas diante dos diversos fenômenos de mercado que viriam a surgir? Continuaram elas cumprindo um papel semelhante ao dos anos 1970, privilegiando artistas e gêneros mais bem posicionados dentro da hierarquia cultural brasileira e mantendo ativa, desse modo, a mediação cultural do "padrão Globo de qualidade" como um filtro? Essas são as principais questôes que serão tratadas a partir da análise da forma como os diversos segmentos do mercado musical surgidos nessas duas décadas foram incorporados nas trilhas.

\section{Pop Rock dos anos 1980}

Em todo o registro historiográfico sobre a música brasileira, os anos 1980 são apontados como o momento de explosão do rock nacional, com as 
apostas das grandes gravadoras bastante voltadas para a exploração e consolidação desse segmento junto a um mercado jovem. As primeiras bandas começam a obter destaque comercial em 1982 a partir de um circuito instaurado em torno de agentes como Rádio Fluminense FM e o Circo Voador no Rio de Janeiro. Nesse contexto também se situavam as principais gravadoras, que se consolidaram progressivamente, desde o estouro da , a partir do I Rock in Rio de 1985 e das expressivas vendagens possibilitadas pelo sucesso momentâneo do Plano Cruzado no Governo Sarney.

No entanto, como lembra Alonso (2011), não há menção ao papel importante das novelas e de suas trilhas nos diversos relatos e análises sobre a consagração dessa geração de grupos de rock. Segundo dados levantados pelo autor, os primeiros artistas que obtiveram destaque comercial no período de estabelecimento do BRock tiveram as portas abertas no espaço das trilhas desde os seus primeiros registros fonográficos. Em 1980, Marina Lima, em um dueto com Caetano Veloso, já estreava em trilhas com a canção "Nosso estranho amor" em "Plumas e Paetês", de 1980. A seguir, foi a vez de Lulu Santos, com "Tesouros da Juventude", do seu primeiro compacto, incluída em "O Amor é Nosso" (1981) e "Tempos Modernos", do seu primeiro LP, em "Sonho de Verâo (1982).

Ainda em "Sonhos de Verão", a Blitz tinha na novela global um importante apoio para tornar "Você náo soube me amar" o sucesso estrondoso que contribuiu para que a banda chegasse à marca de 1 milhão de cópias vendidas de seu compacto. Além disso, a novela contou ainda com a também estreante banda Rádio Táxi, com a música "Coisas de Casal”. Em 1983, foi a vez de Ritchie despontar em "Pão Páo, Queijo Queijo" com "Menina Veneno", que se tornou outro grande hit da época, levando o cantor a ser o maior vendedor de discos do ano. Nessa novela, o Barão Vermelho também era apresentado com "Down em Mim" e, no mesmo ano, tinha "Você me acende" incluída em "Louco Amor".

A conclusão é a de que o espaço das trilhas na TV Globo foi fundamental para o surgimento do BRock, já que, desde antes (mas também durante e depois) do estabelecimento e da consolidação do circuito estabelecido em torno da Rádio Fluminense e do Circo Voador, houve apostas em novos nomes do pop-rock, contribuindo para forjar os primeiros hits e estabelecer os primeiros artistas do segmento no mercado fonográfico. Segundos dados levantados para a produção deste artigo, entre "Sonho de Verão" de 1982 e o final de 1985, Herva Doce, Gang 90 e Absurdetes, Ultraje a Rigor, Magazine, Paralamas do Sucesso, Lobão \& os Ronaldos, Kid Abelha \& os Abóboras Selvagens, Eduardo Dusek e Arnaldo Brandão somam-se aos demais citados obtendo o espaço de 33 faixas em 19 LPs lançados no período.

A partir do ano seguinte, percebe-se um salto na média dessa presença, mantida até o fim da década, com o lançamento de, dentre outros, Engenheiros do Hawaii e Capital Inicial, além da continuidade de boa parte dos anteriormente citados com novas faixas. Em 1986, os grupos de rock dos anos oitenta ocuparam 17 faixas dos 5 LPs de trilhas lançados (sendo que em um deles, provavelmente por 
se tratar de uma novela "de época", não contou com nenhuma de suas gravaçóes). Em 1987, obtiveram 24 cançôes em 6 LPs (dois deles de novelas "de época” e com apenas uma canção gravada por Leo Jaime). No ano seguinte, 12 músicas em 4 LPs (mais um deles de novela "de época" e que não contou com nenhuma de suas gravaçóes). Já em 1989, foram 16 cançóes gravadas em 6 LPs lançados (contando com outra novela "de época" e sem participação de artistas do BRock). ${ }^{3}$

\section{Música Sertaneja}

Os dados levantados por Alonso (2011) apontam que durante o boom comercial da música sertaneja no mercado fonográfico, entre 1987 e 1994, a presença das cançóes dos artistas do segmento nas trilhas era bastante desproporcional ao sucesso obtido pelas suas cançóes. Dentre as quase 500 faixas presentes no repertório de 40 discos lançados nesse período, apenas 13 delas se tratavam de gravaçóes de artistas do segmento, o que representa uma média de pouco mais de 1,5 músicas por ano no período em questáo contra mais de 8 do repertório do pop-rock entre 1982 e 1985 e mais de 17 entre 1986 e 1989, conforme os dados apurados e apresentados em tópico anterior.

Ao contrário do que ocorreu com os primeiros anos de BRock, a imensa maioria dos grandes hits que solidificaram no star system musical nacional artistas sertanejos como Leandro \& Leonardo, Zezé di Camargo \& Luciano e Chirtãozinho \& Xororó naquele período não passou pela mediação das telenovelas globais. Além disso, das 13 músicas incorporadas pelas suas trilhas, apenas cerca da metade era composta por eles mesmos. A primeira canção, "No Rancho Fundo", presente em "Tieta" (1989), tratava-se de um clássico do repertório caipira, composto por Ary Barroso e Lamartine Babo em 1931. Representante de uma estética da qual os modernos sertanejos que a gravaram (Chirtãozinho \& Xororó) se afastavam com suas inovaçôes antenadas com elementos da música pop internacional naquele momento, a canção era legitimada pela tradiçáo cultivada pela $\mathrm{MPB}$ sobre o ideal acerca do universo rural. A segunda, "Luar do Sertão", composta por Catulo da Paixão Cearense e João Pernambuco em 1914 (e imortalizada por Luiz Gonzaga décadas depois), foi gravada por Roberta Miranda para o $2^{\circ}$ disco da trilha da mesma novela (1989), tratando-se de mais um exemplo da força da tradição da estética caipira para legitimar a incorporação dos sertanejos nas trilhas.

Além disso, "Eu te amo" e "Eu só penso em você" (as duas únicas gravadas por Zezé di Camargo \& Luciano em "Perigosas Peruas", de 1992, e em "Fera Ferida", na virada do ano seguinte para 1994) tratavam-se de versóes de cançôes do repertório pop-rock internacional consagrado ("And I Love You", dos Beatles, e "Always on my mind", de Elvis Presley), o que reforça a ideia da necessidade de legitimação para a inclusão dos sertanejos no repertório das telenovelas da TV Globo, nos casos em questão pela mediação de outra via estética que também gozava de maior prestígio cultural. As companhias do cantor country americano Willie Nelson e de um expoente da MPB como Fagner nas faixas gravadas pelos sertanejos são indícios da necessidade de doação de capital simbólico para a sua incorporação nas novelas. 
Se representantes da música brega já se faziam presentes nas trilhas em uma proporção maior do que na década anterior e com músicas de seu próprio repertório, as barreiras colocadas para a inclusão dos sertanejos modernos apontam para a atualidade ainda naquele momento da força da mediação do "padrão Globo de qualidade" e do processo de higienização sonora levantada por Araújo (2002). Ao contrário dos cantores cafonas dos anos 1970, contudo, os sertanejos encontraram espaços cativos em outros programas da Rede Globo, o que pode ter contribuído para a impressão de que tiveram o suporte amplo, total e irrestrito da emissora para a sua consagraçáo comercial a ponto de que a sua sonoridade fosse reconhecida historicamente como a "trilha sonora da Era Collor" e principais responsáveis pela decadência do BRock no mercado. No entanto, esta relação foi muito mais complexa do que geralmente se supóe, com o espaço das trilhas sonoras representando uma significativa resistência, já que os artistas do pop-rock dos anos 1980 continuavam a ter mais lugar do que os sertanejos. Entre 1990 e 1992, período em que Fernando Collor esteve na presidência do país, foram incorporadas 19 faixas de Paralamas (4), Lulu Santos (3), Léo Jaime, Lobão, Biquini Cavadão e Kid Abelha, dentre outros, contra apenas 7 dos sertanejos.

\section{Axé Music}

passageiro do final dos anos 1980, costumam apontá-la como uma "onda" produzida pelo carnaval baiano e capitaneada pela mídia de alcance nacional, ainda que, como gênero, a sonoridade da lambada tenha origem no Pará, na mistura entre o carimbó e a sonoridade característica do Caribe. Pode-se supor que a sonoridade vinculada ao carnaval de Salvador que receberia o rótulo "axé music" foi incorporada ao mercado fonográfico com papel decisivo da Rede Globo e das trilhas de suas novelas de modo similar ao da lambada, já que os artistas que representaram o segmento teriam sido inicialmente divulgados e produzidos justamente no período de auge da lambada. ${ }^{4}$

Depois de estrear em novela em 1987 com uma parceria legitimadora com Caetano Veloso com uma música sem apelo para dança ("É tão bom”), coube a Luiz Caldas, reconhecido como o pai da música axé, gravar a trilha da abertura na novela "Tieta", de 1989, uma música homônima ao título da produção, no mesmo ano em que Beto Barbosa tinha "Adocica" divulgada em "Sexo dos Anjos". Em "Gente Fina", novela de 1990 que divulgou o hit "Dançando Lambada", da Kaoma, Sarajane aparecia em uma das faixas da trilha com o seguinte medley de músicas: "Ela Sabe Mexer/ Abre a Roda, Morenal Roda de Sambal Beco do Amor 2". Na trilha de "Lambateria Sucata", também em 1990, a cantora Margareth Menezes podia ser ouvida com a faixa "Marmelada (Bas Moin Laia)", incluída posteriormente em seu segundo LP, lançado em 1991. Margareth Menezes já havia solidificado um hit quatro anos antes ("Faraó - Divindade do Egito") e lançado o seu primeiro LP em 1988, não tendo sido, portanto, lançada com essa articulação com a telenovela, mas com clipe produzido pelo Fantástico.

No entanto, o maior fenômeno da música baiana a definir o rótulo axé nesses primeiros anos do segmento viria com Daniela Mercury, lançando 
os discos "Daniela Mercury" (1991) e "O Canto da Cidade" (1992), nos quais as duas primeiras cançóes que se tornaram grandes hits radiofônicos ("Swing da Cor" e "O Canto da Cidade") também não frequentaram as trilhas das telenovelas da TV Globo. As primeiras inclusóes da cantora foram com as canções "Só pra te mostrar", em "Renascer" (1993), lançada no disco de 1992, e "Sempre Te Quis", em "Quatro por Quatro" (1994), já de seu terceiro disco. Ambas fugiam da sonoridade típica da música baiana. As músicas eram baladas de compositores que também não tinham ligação com o axé (como Herbert Vianna), o que também aconteceria com a próxima canção incluída em disco de trilha, "À Primeira Vista" (da novela "Rei do Gado", em 1996), composta por Chico César, que se tornaria um dos maiores expoentes da nova MPB naquele momento.

No mesmo ano em que Daniela Mercury havia sido incluída pela primeira vez, a Banda Beijo, após lançar três discos independentes, também teria uma canção registrada na trilha de "Mulheres de Areia" (1992), composta pelo prestigiado artista da MPB Gilberto Gil, contribuindo assim para legitimar a sua incorporação.

Netinho, cantor do grupo logo depois seguiria carreira solo, conhecendo um sucesso ainda maior do que o da Banda Beijo a partir do sucesso de "Menina", faixa incluída na novela "Tropicaliente", de 1994. De 1995 a 1999, o cantor teria mais cinco incluídas, mesmo número atingido pela Banda Eva de sua então vocalista Ivete Sangalo, mostrando-se uma ferramenta importante para o estabelecimento de ambos os artistas no mercado. Além desses, Chiclete com Banana, Banda Cheiro de Amor, Márcia Freire, Ricardo Chaves foram outros nomes que tiveram pelo menos uma canção incorporada ao repertório das trilhas, compondo um número mais expressivo do que o do pagode romântico, apesar da maior variedade de artistas deste segmento a atingir grande sucesso comercial no período. Nesse mesmo período, também obtiveram canções incluídas os representantes do pagode baiano (Companhia do Pagode; GeraSambal É o tchan; TerraSamba), geralmente disponibilizado nas prateleiras das lojas dentro do rótulo axé music ou música baiana, mesmo como uma sonoridade diferenciada das bandas de trio e dos blocos de origem afro. A novela "Malhação", por meio de seus 7 discos de trilhas lançados, destaca-se como um espaço privilegiado em que a "música baiana" perde em participação apenas para representantes do segmento pop-rock no mercado nacional, sendo bem mais aproveitada do que os representantes do sertanejo, da MPB e até mesmo do "pop-dance" (de artistas como Patrícia Marx e Fernanda Abreu). No entanto, a necessidade de consagração por meio da captura de capital simbólico proveniente de artistas mais bem localizados na hierarquia cultural também aparece neste segmento, como exemplificam as cançóes "Is this love" de Bob Marley, gravada pelo TerraSamba, e "Você é linda" de Caetano Veloso, registrada por Netinho.

\section{Funk Carioca}

Depois de estrear em trilhas com um dos seus primeiros registros fonográficos, a cômica "Feira de Acari", do MC Batata, em "Barriga de Aluguel" 
(1990), o funk carioca reapareceu ainda com "Nojento", novamente do MC Batata, em "Araponga" (1990), e com "Rap da Rapa", gravada por Ademir Lemos, em "O dono do mundo" (1991). A partir daí, há apenas um registro de música incluída em disco de trilha:

"Xereta", de Claudinho e Buchecha, em "Suave Veneno", de 1999. Um eventual conflito de interesses entre a TV Globo e o principal agente do circuito do gênero (a equipe Furacão 2000) pode contribuir para explicar o pouco interesse das trilhas no funk para além de qualquer questão de ordem estética e simbólica, visto que, a partir desse momento, a equipe já alugava espaço em outras emissoras para divulgar os artistas. A explosão do funk que levou grandes gravadoras a investirem, em 1995, nas carreiras de duplas como Cidinho $\&$ Doca e na de maior sucesso, Claudinho \& Buchecha, não obteve a parceria das telenovelas, ainda que o funk carioca fosse divulgado na TV Globo pela apresentadora Xuxa, por exemplo.

\section{Pagode Romântico}

Entre 1991, lançamento do primeiro disco do grupo Raça Negra, e 1999, apenas sete cançóes de grupos de pagode romântico foram incluídas nas trilhas: 1) "Seja Mais Você", do Grupo Raça, em "O dono do mundo" (1991); 2) "Tiro ao Álvaro", do Raça Negra, em "Mapa da Mina" (1993); 3) "Pecado Capital", do Só Pra Contrariar, em "Pecado Capital” (1998); 4) "SNS (Só No Sapatinho)", do Grupo Só no Sapatinho, em (1998); 5) "Pela Vida Inteira", do Kiloucura, em "Suave Veneno" (1999); 6) "Machuca Demais" do Só Pra Contrariar e; 7) "Rachadinho", do Soweto, em "Andando nas Nuvens" (1999).

A relação das trilhas com o pagode romântico guarda semelhanças com a da música sertaneja em seu boom mercadológico. "Pecado Capital" e "Tiro Ao Álvaro", os primeiros registros em trilhas de dois dos grupos mais bem sucedidos comercialmente (no caso do Raça Negra, o único) tratam-se de regravaçóes de nomes consagrados do samba (Paulinho da Viola e Adoniran Barbosa) que gozavam (e gozam) de um maior prestígio dentro da hierarquia cultural brasileira, tal como ocorrera com as primeiras gravaçôes de Zezé di Camargo \& Luciano, Roberta Miranda e Chirtãozinho \& Xororó, na tentativa de legitimar a sua incorporação nesse seleto repertório. Apenas duas das cançôes escolhidas (4 e 5) foram os maiores hits de suas respectivas bandas de pagode, em um momento inicial em que diversos grupos já haviam gravado vários discos de grande alcance. Relacionando o pequeno número de faixas com a extensa coleção de hits do segmento, não é difícil perceber que a imensa maioria dos sucessos comerciais do pagode não foi forjada com a contribuição da participação em trilhas.

Além disso, grupos com muitos hits na década de 1990 como Negritude Jr ("Que Dure para Sempre”, "Gente da Gente", "Tanajura", "Vem pra cá”, etc) e Molejo (de "Caçamba", "Paparico", "Cilada", "Brincadeira de Criança", "Dança da Vassoura”, etc) nunca sequer frequentaram a seleção das trilhas. Entre 1996 e 1997, período em que o pagode obteve seus índices mais expressivos de vendagens em um contexto econômico favorável ao farto lucro das majors, nenhuma música dos artistas relacionados ao pagode romântico foi incorporada, 
cabendo a Martinho da Vila, cantor bem mais legitimado e posicionado na hierarquia musical nacional, representar a vertente do samba/pagode em "Vira Lata" (1996) com "Devagar, devagarinho", em momento de forte retomada do seu sucesso comercial.

Trata-se, portanto, de uma falácia qualquer tentativa de atribuir à TV Globo, dentro do rótulo "grande mídia", o privilégio para que o pagode romântico firmasse a sua popularidade comercial na década. Na complexa atuação da televisão com a indústria da música, ao menos em relação ao poderoso espaço das telenovelas globais e de suas trilhas sonoras, os grupos de pagode romântico foram claramente desprestigiados, ainda que transitassem por outros programas da emissora, com participaçóes em eventuais especiais.

\section{Pop Rock nos anos 1990}

Se o pagode romântico não pôde encontrar nas trilhas sonoras das novelas globais um aliado efetivo para atingir a sua expressividade mercadológica obtida ao longo da década de 1990, algumas bandas do segmento pop-rock que surgiram na mesma década tiveram esse suporte desde o início de sua trajetória fonográfica. Em 1993, ano de lançamento do seu primeiro álbum, o Skank emplacou duas das cançóes que o compunham: "Gentil Loucura", em "O Mapa da Mina" e "O Homem Que Sabia Demais", em "Olho no Olho". A banda Chico Science \& Nação Zumbi teve duas cançôes de seu primeiro disco em novelas: "A Praiera" em "Tropicaliente" (1994) e "A Cidade", em "Irmãos Coragem" (1995). O Cidade Negra, em seu segundo disco, mas que marcava uma virada estética do seu reggae mais em direção ao pop com a estreia do vocalista Toni Garrido, também obteve participaçóes com "Pensamento" em "Tropicaliente" (1994) e "A Sombra da Maldade" em "Irmãos Coragem" (1995).

Um relevante canal para a tentativa de estabelecimento dessas bandas e da renovação do pop-rock naquele período foi a novela "Malhação", que estreou em 1995 e se mantém no ar até hoje com renovaçóes constantes de suas tramas, elenco e trilha sonora. Na trilha lançada em 1996, o Pato Fu emplacou "Sobre o Tempo", do $2^{\circ}$ disco (e $1^{\circ}$ com o auxílio de uma grande gravadora desde a sua produção), enquanto o Charlie Brown Jr teve "Proibida Pra Mim" do seu $1^{\circ}$ disco incluída na de 1998, a qual também contava com "Hip Hop Rio" do Planet Hemp, já em seu $2^{\circ}$ álbum. Em outra trilha da mesma novela, O Rappa tinha a canção "Vapor Barato" do seu 20 disco incluída.

Cidadão Quem, Maskavo Roots, Tequila Baby e Penélope foram outras apostas das trilhas em bandas novas do segmento pop rock nos anos 1990, também com canções de seus discos de estreia inseridos em trilhas de "Malhação".

\section{MPB}

Ainda que tenha havido laços mais fortes com um ou outro segmento surgido nas décadas de 1980 e 1990, o papel ativo das trilhas na renovaçáo da MPB como uma categoria que representa um segmento de mercado perdura pelas décadas pesquisadas. 
Diversos artistas tiveram cançóes de seus primeiros discos lançados em novelas. Marisa Monte, com "Bem que se quis" em "O Salvador da Pátria" (1989); Paulinho Moska, com "Será Que Sou Eu”, em "Olho no Olho" (1993); Zeca Baleiro, com "Bandeira" em "Por Amor" e "Heavy Metal do Senhor", em "Era uma vez" (1997), são alguns exemplos do fenômeno que se repete com Adriana Calcanhoto, Zélia Duncan, Jorge Vercilo e Ana Carolina ao longo dos anos 1990. O cantor Lenine, por exemplo, já era uma aposta na trilha de "Lua Cheia de Amor", em 1990, com "Alpinista Social”, muito antes de demarcar lugar cativo no mercado fonográfico a partir de 1997 com o disco "O dia em que faremos contato", do qual, no ano seguinte, teve uma canção incluída na novela "Era uma vez". Além desses artistas que despontaram no star system da indústria musical com participaçôes de suas cançôes nas telenovelas, é notável a forte permanência de nomes da MPB que surgiram para o mercado fonográfico nas décadas de 1960 e 1970 e tiveram forte presença nas trilhas deste período. Entre 1995 e 1999, cinco dos campeões históricos de participaçóes como Gal Costa, Caetano Veloso,

Gilberto Gil, Milton Nascimento e Djavan totalizaram 19 faixas, superando em conjunto o número de participaçóes de todos os artistas da música axé ou do pagode romântico.

\section{Conclusões:}

O papel da Rede Globo na cultura brasileira é bastante complexo e sua relação com a indústria da música é um campo interessante a ser explorado para compreendê-lo.

Percebidas como um lugar de resistência da noção de "bom gosto" por Araújo (2002), as trilhas sonoras da telenovela, mediadas pela implementaçáo do "padrão Globo de qualidade" e de seu ideal higienizador na década de 1970, serviram como importante instância de legitimação mercadológica de artistas da MPB do período, enquanto afastava-se a música cafona com grande sucesso comercial e de maior apelo entre as camadas mais pobres da populaçáo brasileira de sua seleção de faixas ao longo da primeira década de sua existência.

No percurso aqui traçado, a preocupação foi compreender melhor o papel das trilhas nos momentos posteriores ao mapeado pelo autor, procurando perceber de que forma essa mídia sonora se aliou aos segmentos musicais estabelecidos a partir da década de 1980, incorporando-os ou não, bem como de que maneira, em sua seleção de faixas. Optou-se por um recorte que privilegiasse a análise de segmentos da música brasileira que se tornaram delimitadores de sua história a partir desse momento, o que acabou deixando de lado alguns importantes, como o Pop vinculado à Dance Music dos anos 1990 e mesmo o samba/pagode de uma forma mais ampla do que a da vertente do pagode romântico do mesmo período.

A partir da análise dos dados apresentados, verificou-se a existência de laços mais fortes com determinados segmentos do que com outros. Se o pagode romântico e a música sertaneja dos anos 1990 sofreram forte resistência, a música axé sofreu menos barreiras, frequentando de maneira mais efetiva o 
repertório das trilhas, o que pode apontar para a hipótese de haver variaçóes no grau de prestígio entre os gêneros mais populares. Mesmo assim, diante do modo como foi incorporado o pop-rock, tanto a da geração dos anos 1980 quanto a dos anos 1990, a necessidade de mediações que legitimassem esses artistas foram maiores. Ao longo de todo esse período, a MPB mostrou-se um segmento que prossegue com forte presença, tanto com nomes que frequentam as trilhas desde os anos 1970 (e que frequentemente contribuem, com seu repertório e participaçóes em gravaçôes, para avalizar a inclusão de artistas de outros segmentos), quanto com apoio e renovação aos que surgiram nas décadas seguintes vinculados ao rótulo.

Se não cumpriram papel absolutamente igual ao dos anos 1970, as trilhas continuaram sendo, ao longo dos 1980 e 1990, um espaço que privilegiou artistas mais bem posicionados dentro da hierarquia cultural brasileira. Apesar disso, vale lembrar que o espaço da música em telenovela, ainda que fundamental pelo grau de exposição diária para um número expressivo de espectadores atrelado a situações dramatúrgicas e personagens que agregam um valor cultural traduzido em reconhecimento das cançôes e de seus intérpretes, não foi e nem é o único em que a Rede Globo atuou ao longo de sua história de articulação com a indústria musical. Outros espaços, como programas de auditório e especiais mensais e de fim de ano, complexificam a compreensão de sua atuação e devem ser levados em consideração em qualquer análise mais aprofundada sobre o papel da emissora na formulação do star system musical brasileiro.

A amplitude do recorte estabelecido para a análise do papel das trilhas explica-se pela ausência de um mapeamento mais geral sobre o objeto. Tratase, portanto, de um mapeamento inicial, mas necessário, já que as trilhas de novelas são um objeto rico a ser mais explorado por pesquisas que tematizam as relaçôes entre TV e indústria da música.

Desse modo, espera-se que o artigo contribua para que pesquisas mais aprofundadas, com enfoques cronológicos e/ou em cima de gêneros mais específicos, venham a enriquecer os debates acerca deste objeto.

\section{Referências Bibliográficas}

ALONSO, Gustavo. O sertão na televisáo. In: Revista ContemporâneaDossiê Contemporaneidade. Niterói: UFF. Ano 1, n.1, 2011.

ARAÚJO, Paulo Cesar de. Eu não sou cachorro não: música popular cafona e ditadura militar. Rio de Janeiro: Record, 2002.

DE MARCHI, Leonardo. Transformaçôes estruturais da Indústria Fonográfica no Brasil 1999-2009: desestruturação do mercado de discos, novas mediaçóes do comércio de fonogramas digitais e consequências para a diversidade cultural no mercado de música. 2011. Tese de Doutorado. Escola de Comunicação, UFRJ, Rio de Janeiro.

DIAS, Márcia Tosta. "Rede Globo e Indústria Fonográfica: um negócio de 
sucesso". In. BRITTOs, Valério; BOLAÑO, César (orgs). Rede Globo: 40 anos de poder e hegemonia. São Paulo: Paulus, 2005, p. 307-324.

MORELLI, Rita C. L. Indústria Fonográfica: um estudo antropológico. São Paulo: Ed.Unicamp, 1991.

NAPOLITANO, Marcos. “A MPB na era da TV”. In: RIBEIRO, Ana Paula Goulart; SACRAMENTO, Igor; SILVA, Marco Antônio Roxo da. História da Televisão no Brasil: do início aos dias atuais. São Paulo: Comtexto, 2010.

KHEHL, Maria Rita. "Eu vi um Brasil na TV”. In: COSTA, Alcir; SIMÓES, Inimá; KHEHL, Maria Rita. Um país no ar: história da TV brasileira em três canais. São Paulo: Brasiliense/FUNARTE, 1986.

ORTIZ, Renato. A moderna tradição brasileira. São Paulo: Brasiliense, 1988.

RIBEIRO, Ana Paula Goulart; SACRAMENTO, Igor; "A renovação estética da TV”. In: RIBEIRO, Ana Paula Goulart; SACRAMENTO, Igor; SILVA, Marco Antônio Roxo da. História da Televisão no Brasil: do início aos dias atuais. São Paulo: Comtexto, 2010.

TOLEDO, Heloísa Maria dos Santos. Som Livre e trilhas sonoras das telenovelas: pressupostos sobre o processo de difusão da música. Anais do XXX Congresso Brasileiro de Ciências da Comunicação. Santos: 2007.1

\section{Notas}

1. Por esse refinamento da racionalização no planejamento das empresas fonográficas, refiro-me ao processo de modernização da estruturaçáo interna das gravadoras multinacionais no Brasil que permitiu com que estas assumissem o gerenciamento das carreiras dos artistas brasileiros em longo prazo, o que está relacionado à consolidação do LP como principal formato do mercado fonográfico, como aponta De Marchi (2011). Em diálogo com o trabalho de Morelli (1991), centrado na geraçáo dos artistas de MPB que surge nos anos 1970, o autor ressalta a importância das mudanças nesse período, caracterizado pelo fato de que os artistas não mais apareciam nos meios de radiodifusão para consolidarem a sua imagem a fim de possibilitarem a gravação e comercialização fonográfica de suas canções posteriormente. Assim, cantores como Fágner, Ednardo e Belchior somente alcançam a televisão e o rádio por meio desse processo de modernização das gravadoras, graças especialmente à criação de departamentos especializados na gestão das carreiras dos artistas. O crescente apuro no planejamento empresarial que rege a racionalização, verificado na indústria fonográfica nesse contexto, acaba remetendo também à tese de Ortiz (1988) a respeito da possibilidade de se falar concretamente de indústria cultural no Brasil apenas a partir desse momento, no qual o processo de modernização, promovida com a contribuiçáo dos governos da ditadura militar, atinge todos os seus setores.

2. O autor é pouco preciso em relação aos dados, mas quando se analisa nas fontes o repertório dos discos nesse contexto, conclui-se que as barreiras para a incorporaçáo dos cafonas foram mais efetivas do que as dificuldades apresentadas pelos artistas 
de MPB em ocupar esse espaço por conta do posicionamento político de oposiçáo ao regime militar que permeava a produção musical de alguns dos seus personagens mais importantes no período inicial de institucionalização das trilhas, como propóe Morelli (1991, p.70). Enquanto, do lado dos cafonas, apenas Benito di Paula teve uma canção dentre os lançamentos ao longo do governo Médici (19691974), Roberto Menescal e Elis Regina eram os mais prestigiados, com 5 e 4 faixas incluídas, respectivamente. Mesmo que nesse período Chico Buarque, Gilberto Gil e Caetano Veloso não tenham sido incorporados, contaram com interpretaçóes de algumas de suas cançóes por outros cantores. Já entre 1975 e 1978, 7 foram as faixas relacionadas aos ditos cafonas, mesmo número atingido individualmente por Gal Costa e Rita Lee, as campeãs em participação nesse segundo contexto, no qual já se podia ouvir Chico Buarque em três faixas. Além disso, é importante compreender que a natureza de sua classificação para a oposição entre música cafona e MPB está baseada na questão da diferença de prestígio cultural, o que também se relaciona à estrutura de mercado que distingue artistas de catálogo e autorais. Assim, o samba de Paulinho da Viola e Beth Carvalho, assim como o rock de Raul Seixas e Rita Lee, são enquadrados como MPB, enquanto o samba de Benito di Paula e Wando é relacionado ao cafona.

3. Os anos 1980 representaram até certo ponto uma virada nos padróes estabelecidos anteriormente, não somente pela adesão ao pop-rock sintonizada com a força emergente do mercado musical, mas, sobretudo, pela incorporaçáo de cantores rotulados como cafonas alijados na década anterior, além do lançamento de novos nomes do segmento rotulado como brega, tal como Joanna, José Augusto e Rosana. Aquele dentre os poucos artistas relacionados ao rótulo de cafona que conseguiu aparecer em trilhas nos anos 1970 (com "Moça", do seu LP de estreia, na novela "Pecado Capital", ambos de 1975), ao longo dos anos 1980 emplacaria 6 cançóes no repertório das novelas globais. Com essa marca, o cantor Wando ultrapassou em participação a maioria dos nomes do BRock, assim como Rosana, com 5 músicas incluídas, batendo grupos como Titâs e Paralamas. Biafra e José Augusto, com 2 cançóes cada, superam as bandas Engenheiros do Hawaii, Capital Inicial e Legiáo Urbana, com apenas 1 cada, mesmo número alcançado por Agepê, Márcio Greick, Gretchen e Agnaldo Timóteo, por exemplo.

4. Classificada à época como cantora de MPB (ou seja, detinha um lugar de prestígio no star system da música), Fafá de Belém foi quem apresentou a lambada como gênero musical, gravando 3 medleys com cançôes do estilo em seu disco de 1987. Um deles foi incorporado à trilha de "Sassaricando" (1987). Em "Gente Fina", de 1990, "Dançando Lambada", canção da banda Kaoma, estava presente (junto com "Morena”, do Fogo Baiano), solidificando o rótulo genérico para a sonoridade que Beto Barbosa já apresentava anteriormente com o sucesso da canção "Adocica", também incorporada a uma novela global, "Sexo dos Anjos", de 1989. Assim, solidificavam a lambada como um segmento de mercado com artistas identificados com a sonoridade do gênero. "Me chama que eu vou" foi a música que embalava a abertura de "Rainha da Sucata", de 1990, protagonizada por bailarinos (incluindo uma dançarina feita de peças de sucata) que diariamente ensinavam alguns dos principais passos da lambada. Gravada pelo cantor enquadrado no rótulo de cafona nos anos 1970 e 1980, Sidney Magal, a canção também tinha o privilégio de abrir o lado A do disco nacional dessa novela. Além dos tradicionais discos dedicados a cançóes nacionais e internacionais, foi lançado um terceiro, chamado "Trilha Sonora complementar - Lambateria Sucata", contendo aquele 
que se transformaria no $2^{\circ}$ hit de Beto Barbosa ("Preta"), que teria ainda uma $3^{a}$ cançâo incluída na trilha de "Tropicaliente" (1994), uma balada já distante da sonoridade da lambada. Esse disco extra de "Rainha da Sucata" continha faixas tanto de novos artistas que buscavam se associar ao fenômeno (Banana Split, Grupo Sucata), quanto por alguns mais antigos, com cançôes "dançantes", mas não necessariamente associadas ao gênero lambada, que alcançaria o seu auge justamente nesse momento, não aparecendo em mais nenhuma trilha depois de frequentar as dessas três novelas em sequência. Os maiores hits do segmento estavam articulados às telenovelas globais, o que atesta a centralidade destas para a sua afirmação mercadológica. 